\title{
CLINICAL USEFULNESS OF THE INTERNATIONAL RENAL RESEARCH INSTITUTE OF VICENZA (IRRIV) SCORE IN THE INTENSIVE CARE SUBJECTS WITH RENAL FAILURE: SINGLE-CENTRE EXPERIENCE
}

DOI: 10.36740/WLek202007115

\author{
Agnieszka Wiorek, Milena Horodecka, Lukasz J. Krzych \\ 'DEPARTMENT OF ANAESTHESIOLOGY AND INTENSIVE CARE, SCHOOL OF MEDICINE IN KATOWICE, MEDICAL UNIVERSITY OF SILESIA, \\ KATOWICE, POLAND
}

\begin{abstract}
The aim: Acute kidney injury (AKI) is a common and clinically important condition that affects both kidney structure and function. International Renal Research Institute of Vicenza (IRRIV) score has been designed to enable early identification of patients who may require renal replacement therapy (RRT). We aimed to assess the usefulness of the IRRIV score in predicting the outcome in the intensive care unit (ICU) patients who may require renal replacement therapy (RRT).

Material and Methods: This retrospective study screened 955 consecutive patients hospitalized in a mixed tertiary ICU between Jan 2015 and Jul 2018. Patients with sCr $>3.5$ $\mathrm{mg} / \mathrm{dl}$ on the first 24 hours post-admission constituted the study group $1(\mathrm{G} 1, \mathrm{n}=54)$. Subjects who underwent RRT based on indications other than elevated sCr level were a study group 2 (G2, n=31). ICU mortality, a need for RRT and ICU length of stay (LOS) were the outcomes.

Results: Median IRRIV score was 5.5 points (IQR 4.5-6.5) in G1 and 3.5 points (IQR 3-5.5) in G2. IRRIV score poorly predicted the need for RRT implementation (AUC=0.652, $95 \% \mathrm{Cl} 0.510-0.776, \mathrm{P}=0.048)$. The IRRIV score failed to predict mortality in both groups ( $\mathrm{G} 1: \mathrm{AUC}=0.610,95 \% \mathrm{Cl} 0.468-0.740, \mathrm{P}=0.16 ; \mathrm{G2}: \mathrm{AUC}=0.530,95 \% \mathrm{Cl} 0.343-0.710$, $P=0.79$ ). No correlation was found between the score and ICU $\operatorname{LOS}(G 1: R=-0.13, P=0.36 ; G 2: R=-0.27, P=0.15)$.

Conclusions: The retrospective analysis of our regional data did not confirm the expected usefulness of the IRRIV score in predicting the need for RRT nor in the prognostication of the patients admitted to the ICU due to renal failure.
\end{abstract}

KEY WORDS: acute kidney injury, International Renal Research Institute in Vicenza score, renal replacement therapy

Wiad Lek. 2020;73(7):1384-1390

\section{INTRODUCTION}

Acute kidney injury (AKI) constitutes a serious clinical condition that affects both kidney structure and function. It may concern $30-40 \%$ of patients treated in the intensive care units (ICU) worldwide [1,2]. There are a plethora of AKI risk factors $[3,4]$. AKI may significantly affect prognosis $[5,6]$.

According to AKIN (Acute Kidney Injury Network) [7] or KDIGO (Kidney Disease: Improving Global Outcomes) [3] guidelines, AKI is classified into stages which are in direct correlation with progression of renal insufficiency [3]. The optimal timing of implementation of renal replacement therapy (RRT) for AKI in ICU subjects is still not well defined and the decision must be made based on clinical and biochemical parameters of volume overload, azotaemia, hyperkalaemia, and acidosis $[1,2,8]$. These factors are considered "classic" indications for RRT [9]. Although AKIN 3 stage or AKIN 2 stage with a documented renal damage (by biomarkers) are believed to be the best thresholds for RRT to start [10,11], there is some evidence that even earlier treatment may improve the outcome in critically ill [12-14]. However, in contrast to the studies promoting the earlier start of RRT, examples of recent trials point towards a favorable strategy of delayed initiation or cannot give an unequivocal answer $[15,16]$.
Several attempts have been made to establish a simple but accurate method of facilitating decision making. IRRIV (International Renal Research Institute of Vicenza) score has been designed to enable early identification of vulnerable patients who may require RRT [17]. Although the first results seemed promising, its clinical utility has not been yet validated externally.

\section{THE AIM}

We aimed (1) to assess the usefulness of the IRRIV score in the prediction of RRT implementation in patients with elevated $\mathrm{sCr}$ concentration, (2) to verify its utility in patients presenting "classic" indications for RRT, and (3) to verify whether the score helps predict the outcome in the ICU setting.

\section{MATERIAL AND METHODS}

\section{STUDY POPULATION}

In this retrospective study, a number of 955 consecutive patients hospitalized between 01.2015 and 07.2018 in a mixed ICU was screened. Then, 865 individuals were excluded due to $\mathrm{sCr}$ level 
Table I. Study group characteristics and procedure-related variables.

\begin{tabular}{|c|c|c|c|c|}
\hline Variable & Category/Unit & G1 $(n=54)$ & G2 $(n=31)$ & Combined G1+G2 (n=85) \\
\hline \multirow{2}{*}{ Sex } & Males & $31(57 \%)$ & $13(42 \%)$ & $44(52 \%)$ \\
\hline & Females & $23(43 \%)$ & $18(58 \%)$ & $41(48 \%)$ \\
\hline Age & (years) & $61(48-72)$ & $65(52-71)$ & $64(50-72)$ \\
\hline APACHE II & (points) & $21(16-29)$ & $21.5(15-28)$ & $21(15-29)$ \\
\hline $\begin{array}{l}\text { Serum creatinine on day } 1 \text { of ICU } \\
\text { admission }\end{array}$ & (mg/dl) & $3.5(2.08-4.42)$ & $1.63(1.17-1.95)$ & $2.42(1.47-3.70)$ \\
\hline eGFR on day 1 of ICU admission & $\left(\mathrm{ml} / \mathrm{min} / 1,73 \mathrm{~m}^{2}\right)$ & $18(12.7-32.3)$ & $44.7(29.6-56.6)$ & $23.8(16.2-48.1)$ \\
\hline Length of ICU stay & (days) & $6.5(3-18)$ & $8(3-19)$ & $7(3-19)$ \\
\hline \multirow[t]{4}{*}{ Length of RRT } & (days) & $3(2-4)$ & $5(2-6.3)$ & $4(2-6)$ \\
\hline & Median (IQR) & $4(4-5)$ & 0 & $4(4-5)$ \\
\hline & G1 & 0 & 0 & 0 \\
\hline & $\mathrm{G} 2$ & 0 & 0 & 0 \\
\hline \multirow[t]{4}{*}{ Chronic Kidney Disease (CKD) stage } & G3a & $2(3.7 \%)$ & 0 & $2(2.4 \%)$ \\
\hline & G3b & $1(1.9 \%)$ & 0 & $1(1.2 \%)$ \\
\hline & G4 & $6(11.1 \%)$ & 0 & $6(7.1 \%)$ \\
\hline & G5 & $8(14.8 \%)$ & 0 & $8(9.4 \%)$ \\
\hline
\end{tabular}

Values are medians, interquartile ranges (Q1-Q3) for quantitative variables, and frequencies and percentages for qualitative variables

Table II. Causes of acute kidney injury in both groups (according to KDIGO [3]).

\begin{tabular}{|c|c|c|c|c|c|}
\hline Risk factors/ Exposures & $\begin{array}{c}\mathbf{G 1} \\
\mathbf{N}=54\end{array}$ & $\begin{array}{c}\mathbf{G 2} \\
\mathrm{N}=31\end{array}$ & $\begin{array}{c}\text { Risk factors/ } \\
\text { Susceptibilities }\end{array}$ & $\begin{array}{c}\mathbf{G 1} \\
\mathrm{N}=54\end{array}$ & $\begin{array}{c}\mathbf{G 2} \\
\mathbf{N}=31\end{array}$ \\
\hline Sepsis & $7(13 \%)$ & $8(25.8 \%)$ & $\begin{array}{c}\text { Dehydration/ } \\
\text { volume depletion }\end{array}$ & $12(22.2 \%)$ & $7(22.6 \%)$ \\
\hline Critical illness & $54(100 \%)$ & $31(100 \%)$ & $\begin{array}{l}\text { Advanced age } \\
\text { (>65yrs) }\end{array}$ & $23(42.6 \%)$ & $14(45.2 \%)$ \\
\hline Circulatory shock & $9(16.7 \%)$ & $4(12.9 \%)$ & Female gender & $23(42.6 \%)$ & $18(58.1 \%)$ \\
\hline Trauma & $5(9.3 \%)$ & 0 & Chronic kidney disease & $17(31.5 \%)$ & 0 \\
\hline $\begin{array}{c}\text { Major non-cardiac } \\
\text { surgery }\end{array}$ & $16(29.6 \%)$ & $8(25.8 \%)$ & $\begin{array}{l}\text { Chronic disease } \\
\text { (heart, lung, liver) }\end{array}$ & $24(44.4 \%)$ & $20(64.5 \%)$ \\
\hline Nephrotoxic drugs & $1(1.9 \%)$ & $1(3.2 \%)$ & Diabetes mellitus & $12(22.2 \%)$ & $8(25.8 \%)$ \\
\hline Radiocontrast agents & $4(7.4 \%)$ & $6(19.4 \%)$ & Cancer & $16(29.6 \%)$ & $8(25.8 \%)$ \\
\hline $\begin{array}{l}\text { Poisonous plants } \\
\text { and animals }\end{array}$ & 0 & 0 & $\begin{array}{c}\text { Anaemia }(\mathrm{F}:<12 \mathrm{~g} / \mathrm{dl} ; \\
\mathrm{M}:<13 \mathrm{~g} / \mathrm{dl})\end{array}$ & $29(53.7 \%)$ & $19(61.3 \%)$ \\
\hline
\end{tabular}

Values are frequencies and percentages for qualitative variables

$<3.5 \mathrm{mg} / \mathrm{dl}$ and/or no other existing indications for RRT. From the group of remaining 90 subjects, five more patients were excluded from further evaluation (length of ICU stay shorter than $24 \mathrm{~h}, \mathrm{n}=2$; transfer to another hospital/unit, $\mathrm{n}=2$; lack of data, $\mathrm{n}=1$ ). Patients' flowchart is depicted in Figure 1 .

Patients with $\mathrm{sCr} \geq 3.5 \mathrm{mg} / \mathrm{dl}$ on the first 24 hours post-ICU-admission (as an accepted indication for RRT implementation [18]) constituted the study group "1" (G1, $\mathrm{n}=54$ ). Subjects who underwent RRT based on occurring indications, regardless of the recorded sCr level staying within reference values, were considered the study group " 2 " $(\mathrm{G} 2, \mathrm{n}=31)$. The rationale for RRT start in $\mathrm{G} 2$ was as follows: acidosis $(n=28)$, anuria $(n=18)$, fluid overload $(n=11)$, sepsis $(n=8)$, and toxic acute renal failure $(n=5)$. Groups $G 1$ and G2 were not interchangeable, meaning no patients from $\mathrm{G} 2 \mathrm{had}$
$\mathrm{sCr}>3.5 \mathrm{mg} / \mathrm{dl}$ during the entire length of ICU stay. 17 patients in $\mathrm{G} 1$ and 0 patients in $\mathrm{G} 2$ had chronic kidney disease (CKD) diagnosed before the ICU admission. However, none of the patients required RRT prior to the ICU admission analyzed in our study. All subjects had continuous RRT (CRRT), either continuous veno-venous hemodialysis (CVVHD, $\mathrm{n}=27$ ), continuous veno-venous hemodiafiltration (CVVHDF, $\mathrm{n}=20$ ) or continuous veno-venous hemofiltration (CVVHF, $\mathrm{n}=1$ ).

\section{DATA EXTRACTION AND ANALYSIS}

Medical and demographic data were retrieved from medical records, with special attention given to the acknowledged AKI risk factors, according to KDIGO guidelines [3], and the acknowledged indications for RRT [9], i.e. excessive fluid over- 

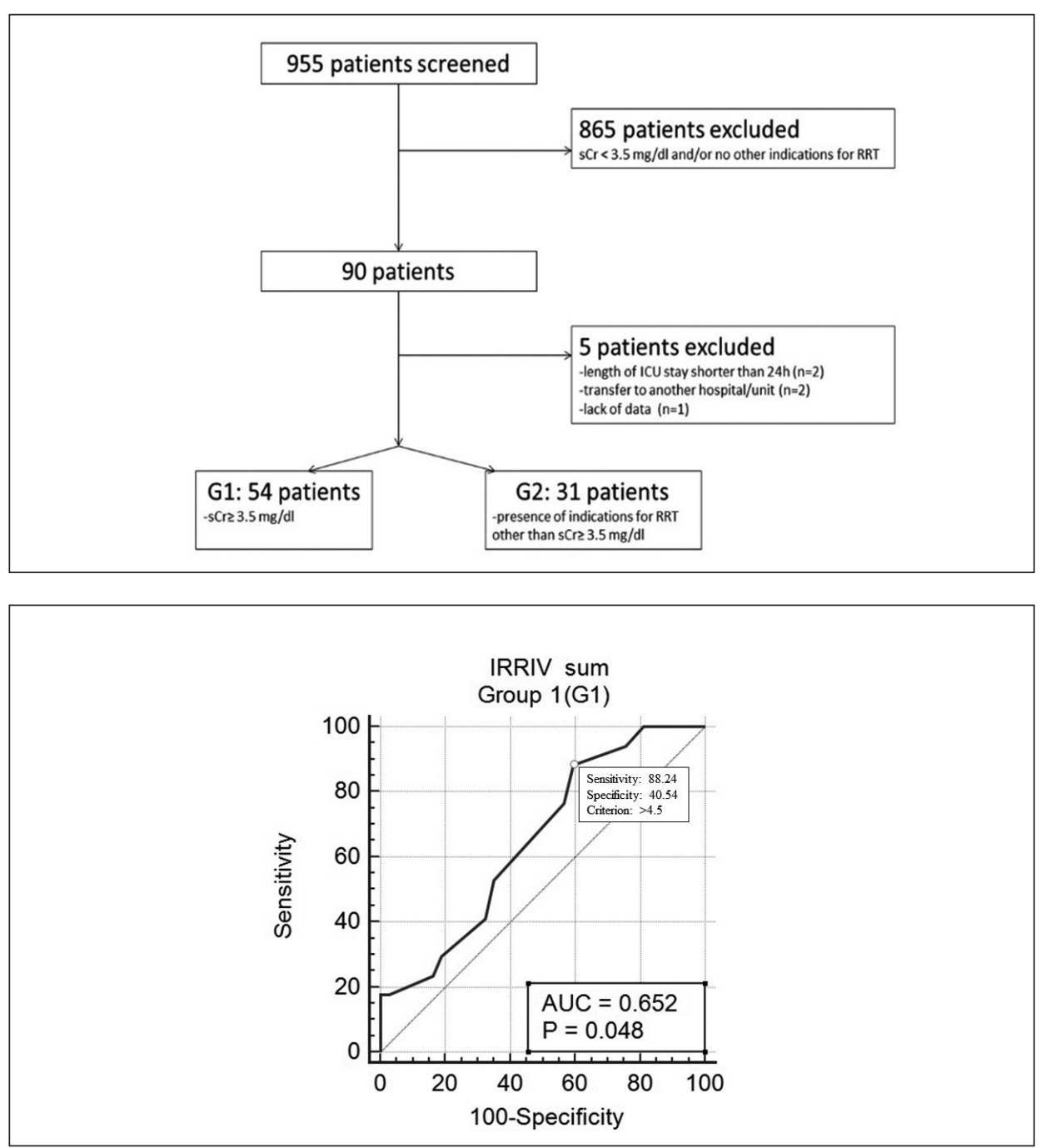

Fig. 1. Flowchart of the study population.

Fig. 2. Prediction of RRT need using the IRRIV score in $\mathrm{G} 1$ patients.
Table III. Parameters of the IRRIV score in both groups (according to Zaragoza et al. [15]).

\begin{tabular}{ccc}
\hline Parameter & $\begin{array}{c}\text { G1 } \\
\text { N=54 }\end{array}$ & $\begin{array}{c}\text { G2 } \\
\text { N=31 }\end{array}$ \\
\hline $\begin{array}{c}\text { Mean arterial pressure } \\
\text { (lowest) } \leq 65 \mathrm{mmHg}\end{array}$ & $26(48.1 \%)$ & $19(61.3 \%)$ \\
\hline $\begin{array}{c}\text { Body temperature } \\
\text { (highest) } \geq 38.2^{\circ} \mathrm{C}\end{array}$ & $5(9.3 \%)$ & $3(9.7 \%)$ \\
\hline $\begin{array}{c}\mathrm{HCO}_{3}{ }^{-} \text {concentration } \\
\text { (lowest) } \leq 23 \text { mmol/l }\end{array}$ & $39(72.2 \%)$ & $23(74.2 \%)$ \\
\hline Urinary output (lowest) $\leq 40 \mathrm{ml} / \mathrm{h}$ & $30(55.6 \%)$ & $23(74.2 \%)$ \\
\hline SOFA renal (highest) $\geq 2$ & $42(77.8 \%)$ & $8(25.8 \%)$ \\
\hline No mechanical ventilation & $9(16.7 \%)$ & $3(9.7 \%)$ \\
\hline Change of sCr $\geq 0.3 \mathrm{mg} / \mathrm{dl}$ & $49(90.7 \%)$ & $18(58.1 \%)$ \\
\hline Fluid accumulation $\geq 10 \%$ & $15(27.8 \%)$ & $11(35.5 \%)$ \\
\hline
\end{tabular}

Values are frequencies and percentages for qualitative variables. SOFASequential Organ Failure Assessment score, sCr-serum creatinine.

load $(>10 \%)$, acidosis ( $\mathrm{pH}<7.15)$, low urine output $(<0.5 \mathrm{ml} /$ $\mathrm{kg} / \mathrm{h}$ for at least 6 hours), sepsis, and acute renal failure (AKIN class 3). IRRIV score for each patient was calculated based on the worst recorded value during the first 24 hours after patient's admission to the ICU with some complementary data taken from the patient's further ICU stay (e.g. sCr value from the day of ICU discharge The score consists of 8 parameters with a threshold value assigned for each of them, i.e. mean arterial pressure, body temperature, serum $\mathrm{HCO}_{3}^{-}$concentration, urinary output, Sequential Organ Failure Assessment (SOFA) renal score, need of mechanical ventilation, change of serum creatinine ( $\mathrm{sCr}$ ) during hospital stay, and fluid accumulation [17]. During the evaluation, a sum of a maximum 11 points could be given to the patients based on their clinical status and laboratory results. Each parameter has a one ascribed value of $1,1.5$ or 2 points exactly. The threshold of $>3.5$ points (including at least one of the renal dysfunction markers) has been accepted as an indication for RRT. [18]

ICU mortality and ICU length of stay (LoS) were considered the outcome. ICU LoS was defined as the time from the ICU admission to either the patient's discharge from the hospital, transfer to another ward or death.

\section{ETHICAL ISSUES}

Under section 21 and 22 of the Act of 5 December 1996 on the Medical Profession [19], due to non-interventional and 

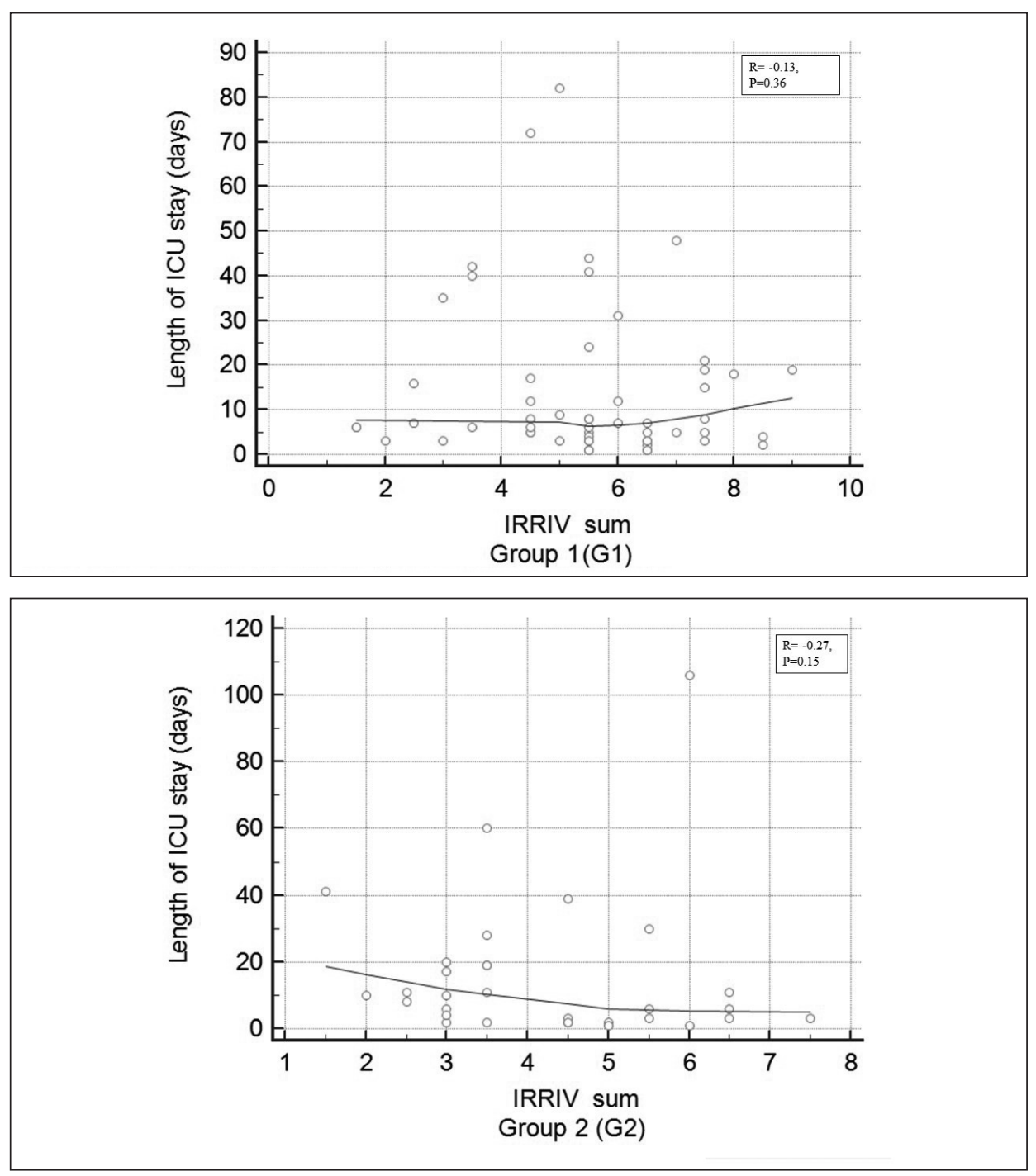

Fig. 3. Scatter diagram for the association between the IRRIV score and ICU length of stay in G1 patients.

Fig. 4. Scatter diagram for the association between the IRRIV score and ICU length of stay in $\mathrm{G} 2$ patients. retrospective design of the study, no approval of the Ethics Committee was required. However, all patients data were obtained in accordance with the national law regulations of personal data management, after the written consent was given by the patients on hospital admission, excluding unconscious patients who required emergency procedures.

\section{STATISTICAL ANALYSIS}

Statistical analysis was performed using MedCalc v.18 software (MedCalc Software, Ostend, Belgium). Quantitative variables were depicted using medians and interquartile ranges (IQR, i.e., 25pc-75pc). The D'Agostino-Pearson test was used to verify their distribution. Qualitative variables were described with frequencies and percentages. Between-group differences for continuous variables were assessed using the Kruskal-Wallis test, while for categorical variables the Chisquared test was applied. ROC curves were drawn and areas under the ROC curves (AUC) were calculated to determine the predictive value of the IRRIV score and the outcome. Correlations were assessed using Spearman's rank coefficient. A p-value $<0.05$ was considered significant.

\section{RESULTS}

G1 consisted of 54 patients ( 31 men, $57 \%$ / median age of 61 years, IQR 48-72). G2 included 31 patients (13 men, $42 \%$ / median age of 65 years, IQR 52-71 Median baseline APACHE II score was 21 (IQR 16-29) in G1 and 21.5 (IQR $15-28)$ in $\mathrm{G} 2$, respectively $(\mathrm{P}=0.89)$.

Detailed characteristics of the study groups are depicted in Table I. Distribution of classic AKI risk factors in both groups is depicted in Table II. Median IRRIV score was 5.5 points (IQR 4.5-6.5) in G1 and 3.5 points (IQR 3-5.5) in $\mathrm{G} 2(\mathrm{P}=0.02)$. Distribution of all constituents of the score in both groups is shown in Table III.

In G1, 17 patients (32\%) had CRRT during ICU stay. Median RRT time was 3 days (IQR 2-4.5) in G1 and 5 days (IQR 2-6) in G2. Median ICU LoS was 6.5 days (IQR 3-18) in $\mathrm{G} 1$ and 8 days (IQR 3-19) in G2, respectively $(\mathrm{P}=0.54)$. Mortality was higher in G2 ( $\mathrm{n}=20,64.5 \%)$ compared to G1 ( $\mathrm{n}=20,37 \%)(\mathrm{P}=0.015)$.

IRRIV score poorly predicted the need for RRT implementation in G1 (AUC $=0.652,95 \% \mathrm{CI} 0.510-0.776, \mathrm{P}=0.048$ ) (Fig. 2). No correlation was found between IRRIV score and ICU $\operatorname{LoS}(\mathrm{G} 1: \mathrm{R}=-0.13, \mathrm{P}=0.36 ; \mathrm{G} 2: \mathrm{R}=-0.27, \mathrm{P}=0.15)$ 


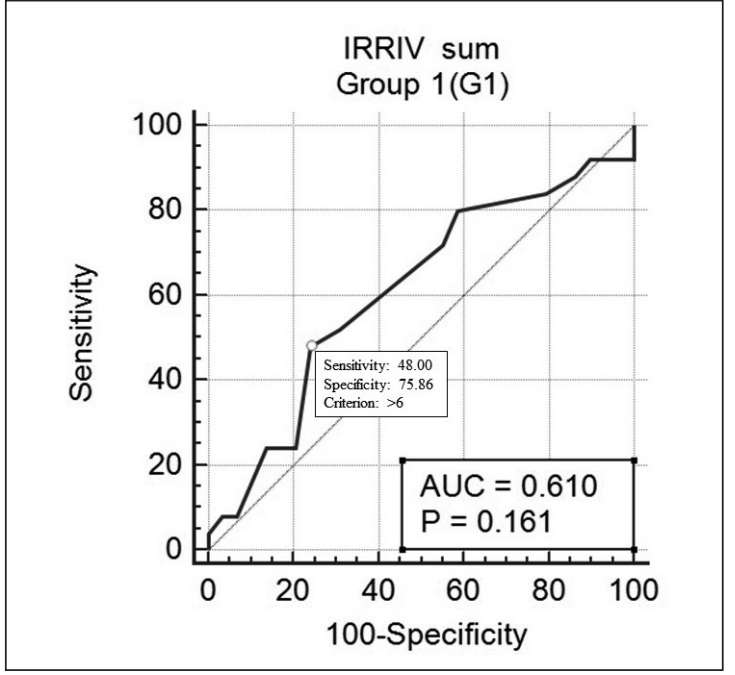

Fig. 5. Prediction of mortality using the IRRIV score in G1 patients.

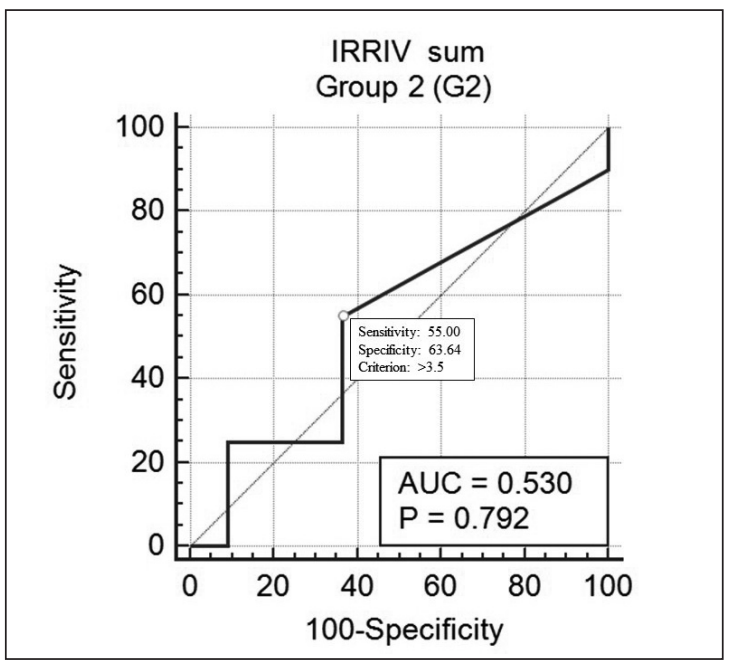

Fig. 6. Prediction of mortality using the IRRIV score in G2 patients.

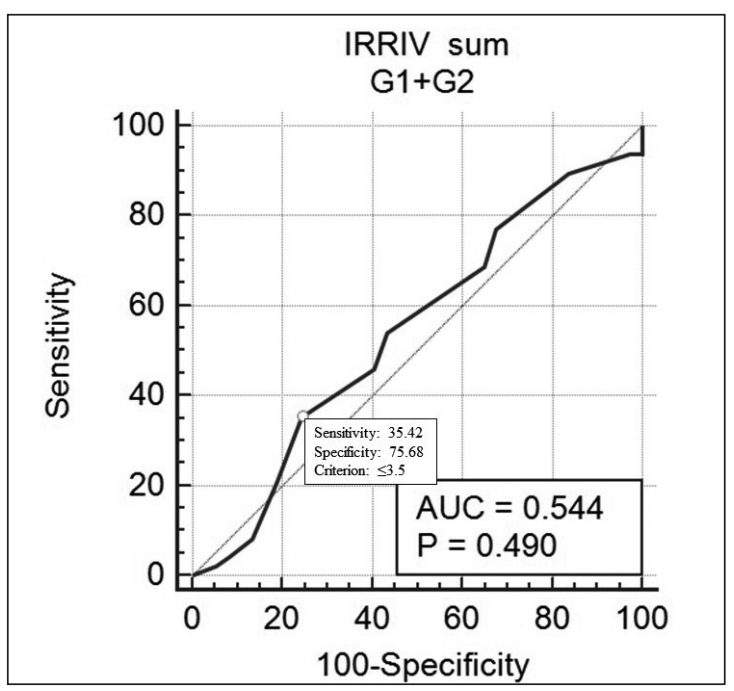

Fig.7. Prediction of RRT need using the IRRIV score in combined G1 and G2 patients.

(Fig. 3-4). IRRIV score failed to predict mortality in both groups (G1: AUC $=0.610,95 \% \mathrm{CI} 0.468-0.740, \mathrm{P}=0.16$; $\mathrm{G} 2$ : $\mathrm{AUC}=0.530,95 \% \mathrm{CI} 0.343-0.710, \mathrm{P}=0.79$ ) (Fig. 5-6).

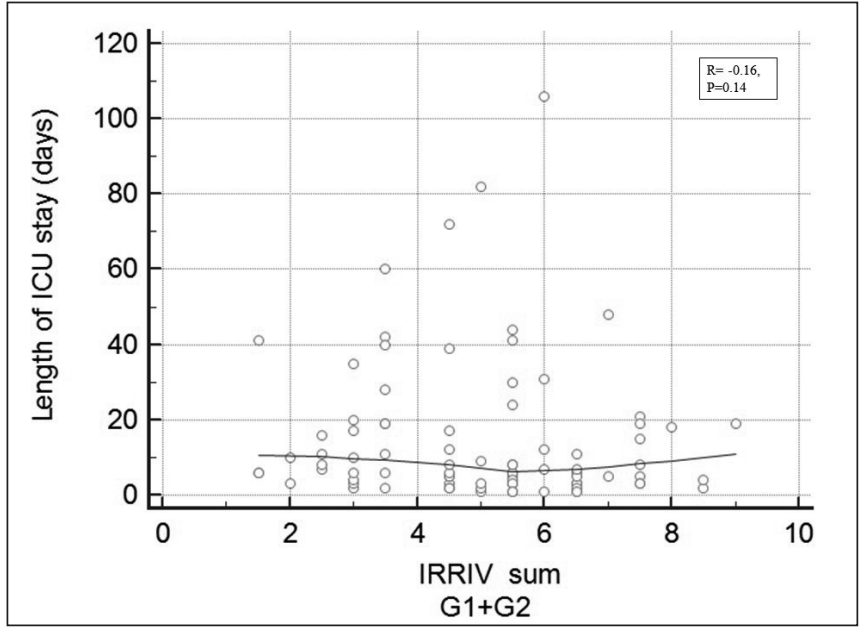

Fig. 8. Scatter diagram for the association between the IRRIV score and ICU length of stay in combined G1 and G2 patients.

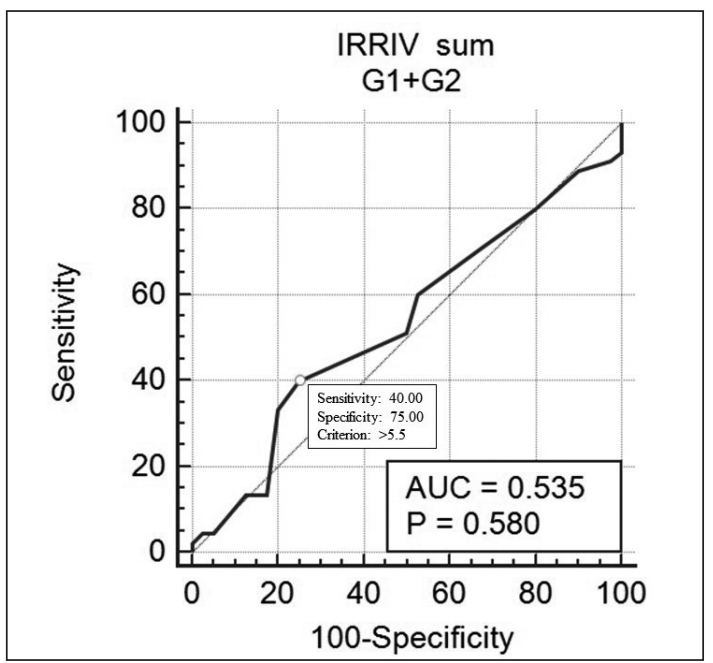

Fig. 9. Prediction of mortality using the IRRIV score in combined $\mathrm{G} 1$ and $\mathrm{G} 2$ patients.

When combined G1 and G2 were analyzed, IRRIV could not predict the need for RRT implementation (AUC $=0.544,95 \% \mathrm{CI}$ 0.433-0.653, $\mathrm{P}=0.490$ ) (Figure 7). No correlation was found between IRRIV score and ICU LoS $(\mathrm{R}=-0.16, \mathrm{P}=0.14)$ (Figure 8). IRRIV score failed to predict mortality (AUC $=0.535,95 \%$ CI $0.424-0.644$, $\mathrm{P}=0.58$ ) (Figure 9).

\section{DISCUSSION}

In this short study, we sought to verify the clinical utility of the IRRIV score in the local academic ICU. The score predicted neither a need for RRT implementation nor the short-term outcome.

Our project was inspired by the original study of Zaragoza et al. who analysed the frequency of RRT, ICU mortality and length of ICU stay [17]. Interestingly, our results are not in line with those from a Vicenza group. In their paper, the score helped predict a need for RRT (AUC $=0.81)$, mortality $(\mathrm{P}<0.001$; AUC not calculated $)$, and $\operatorname{LoS}(\mathrm{P}<0.001)$. There are, however, some discrepancies between the studies in terms of the number of subjects, mode of participants' 
selection, and distribution of baseline AKI risk factors (sCr, SOFA renal score) which make direct comparisons impossible. The original study population comes from the NEFROINT (NEFROlogia e Cura INTensiva) Investigation group database which is a prospectively collected database of 10 Italian ICUs and it was focused on the epidemiology and risk factors of AKI in the ICU [20,17]. Our patients came from a single-centre, mixed ICU, therefore our study group included patients in a critical state, with disorders of various backgrounds e.g. medical, post-operative, neurological, etc. one ought to remember that we didn't aim to monitor the exact number of parameters as recorded by the Vicenza team, but we directly based on a final model constructed by them. Our investigation generally focused less on the time and events prior to the ICU hospitalization, e.g. pre-hospitalization sCr levels and previous exposure to toxics, which usually are difficult to assess. Moreover, Zaragoza and colleagues implemented a control group of patients with a relatively low serum creatinine level (mean value of $0.9 \mathrm{mg} / \mathrm{dl}$ ). The rationale to investigate the G1 group in our study was to check if the score was truly decisive in starting RRT in "borderline" patients with elevated creatinine concentration. As a result, we chose the critically ill patients whose sCr was high enough to suggest the need for renal support. Then we evaluated the subsequent IRRIV score parameters to confirm the need for therapy and checked if it was indeed delivered.

Unfortunately, there is a paucity of international data enabling further comparisons regarding the utility of the IRRIV score. Particularly, there is a lack of evidence on validation of the score in different ICU populations (i.e. surgical, septic, cardiac) or in different clinical scenarios (i.e. non-ICU). Our paper is not an exact copy of the original study, rather a reimagination aimed at congruent goals. From this point of view, we believe our study to be novel in this field.

Despite the fact that RRT has become an integral part of modern critical care, identifying the optimal timing and optimal indications for RRT remain difficult in ICU practice. Unfortunately, the findings of recently published meta-analyses are inconclusive. Including 9 RCTs, Lai et al. [21] revealed that compared with "later" RRT, "earlier" initiation of treatment did not show beneficial impacts on patient outcomes. However, a lower rate of death was observed among surgical patients and in those who underwent CRRT. No beneficial effect of "earlier" start of RRT was found by Yang and colleagues in their comprehensive meta-analysis of RCTs [22]. Besen et al. [23] revealed that early initiation of RRT was associated with lower mortality in prospective and retrospective observational studies, however, after excluding low-quality papers, the relationship remained insignificant. Also, a meta-analysis with trial sequential analysis of RCTs documented no benefit of the early use of RRT [24]. There is a serious methodological problem of definition of "early" and "late" RRT implementation, which differs significantly between studies. We may, therefore, assume that conclusions on the relationship between RRT timing and the outcome are biased, and the additional value of the IRRIV score is of low importance in this context.

\section{STUDY LIMITATIONS}

One should bear in mind potential limitations of our study, including relatively small study group with high sCr, lack of a control group with patients only "at risk" of RRT (AKIN stage 1 and 2), lack of calculated AUC values for each independent IRRIV score parameters due to limited number of subjects, no precise information regarding the entire population of 955 ICU patients with regard to AKI risk factors, limited number of variables included in statistical analysis (i.e. cause of admission), resulting in unclear determination as to what extent they affected the outcome in logistic regression. It also needs to be underlined that a relatively low percentage of subjects received RRT. Nonetheless, out of 955 examined cases, only the chosen 85 presented any indications for renal support.

\section{CONCLUSIONS}

We may conclude that the retrospective analysis of our regional data did not confirm the expected usefulness of the IRRIV score in predicting the need for RRT nor in the prognostication of the patients admitted to the ICU due to renal failure.

\section{REFERENCES}

1. Hoste EA, Bagshaw SM, Bellomo R, et al. Epidemiology of acute kidney injury in critically ill patients: the multinational AKI-EPI study. Intensive Care Med. 2015;41(8):1411-23. D0I: 10.1007/s00134-015-3934-7.

2. Bellomo R, Kellum JA, Ronco C. Acute kidney injury. Lancet 2012;380(9843):75666. D0l: 10.1016/S0140-6736(11)61454-2.

3. Kidney Disease: Improving Global Outcomes (KDIGO) Acute Kidney Injury Work Group. KDIGO Clinical Practice Guideline for Acute Kidney Injury. Kidney International Supplements 2012;2:1-138. D0I:10.1038/ kisup.2012.2.

4. Czempik P, Cieśla D, Knapik P, Krzych ŁJ. Risk factors of acute kidney injury requiring renal replacement therapy based on regional registry data. Anaesthesiol Intensive Ther. 2016;48(3):185-90. D0l: 10.5603/ AlT.a2016.0033.

5. Singbart K, Kellum JA. AKI in the ICU: definition, epidemiology, risk stratification, and outcomes. Kidney Int. 2012;81(9):819-25. DOI: 10.1038/ki.2011.339.

6. Czempik P, Cieśla D, Knapik P, Krzych $Ł$. Outcomes of patients with acute kidney injury with regard to time of initiation and modality of renal replacement therapy - first data from the Silesian Registry of Intensive Care Units. Polish Journal of Thoracic and Cardiovascular Surgery 2016;13(2):122-9. D0l:10.5114/kitp.2016.61045.

7. Lopes JA, Jorge $S$. The RIFLE and AKIN classifications for acute kidney injury: a critical and comprehensive review. Clin Kidney J. 2013; 6(1): 8-14. DOl: $10.1093 / \mathrm{ckj} / \mathrm{sfs} 160$.

8. Libório AB, Leite TT, Neves FM, Teles F, Bezerra CT. AKI complications in critically ill patients: association with mortality rates and RRT. Clin. J. Am. Soc. Nephrol. 2015; 10(1): 21-8. D0I: 10.2215/CJN.04750514.

9. Ricci Z, Romagnoli S, Ronco C. Renal Replacement Therapy [version 1; referees: 4 approved]. F1000Research 2016; 5(F1000 Faculty Rev): 103. DOI: 10.12688/f1000research.6935.1. 
10. Xiong J, Tang X, Hu Z, Nie L, Wang Y, Zhao J. The RIFLE versus AKIN classification for incidence and mortality of acute kidney injury in critical ill patients: A meta-analysis. Sci. Rep. 2015; 5: 17917. D0l: 10.1038/ srep 17917.

11. Leite TT, Macedo E, Pereira SM, et al. Timing of renal replacement therapy initiation by AKIN classification system. Crit Care 2013; 17(2): R62. DOI: 10.1186/cc12593.

12. Ronco C, Ricci Z, De Backer D, et al. Renal replacement therapy in acute kidney injury: controversy and consensus. Crit Care 2015; 19: 146. DOI: 10.1186/s13054-015-0850-8.

13. Vijayan A, Palevsky PM. Dosing of renal replacement therapy in acute kidney injury. Am. J. Kidney Dis. 2012; 59(4): 569-76. Dol: 10.1053/j. ajkd.2011.11.035.

14. Fieghen $H$, Wald $R$, Jaber BL. Renal replacement therapy for acute kidney injury. Nephron Clin Pract. 2009; 112(4): 222-9. D0I: 10.1159/000224788.

15. Gaudry S, Hajage D, Schortgen F, et al. Timing of Renal Support and Outcome of Septic Shock and Acute Respiratory Distress Syndrome. A Post Hoc Analysis of the AKIKI Randomized Clinical Trial. Am J Respir Crit Care Med. 2018; 198(1): 58-66. DOI: 10.1164/rccm.201706-12550C.

16. Barbar SD, Binquet $C$, Monchi $M$, Bruyère $R$, Quenot JP. Impact on mortality of the timing of renal replacement therapy in patients with severe acute kidney injury in septic shock: the IDEAL-ICU study (initiation of dialysis early versus delayed in the intensive care unit): study protocol for a randomized controlled trial. Trials 2014; 15: 270. DOl: 10.1186/1745-6215-15-270.

17. Zaragoza JJ, Villa G, Garzotto F, et al. Initiation of renal replacement therapy in the intensive care unit in Vicenza (IRRIV) score. Blood Purif. 2015; 39(1-3): 246-57. D0I: 10.1159/000381009.

18. Schneider AG, Eastwood GM, Seevanayagam S, Matalanis G, Bellomo R. A risk, injury, failure, loss, and end-stage renal failure score-based trigger for renal replacement therapy and survival after cardiac surgery. J Crit Care 2012; 27(5): 488-95. D0I: 10.1016/j.jcrc.2012.02.008.

19. Act of 5 December 1996 on the Medical Profession, Available online: prawo.sejm.gov.pl: http://prawo.sejm.gov.pl/isap.nsf/DocDetails. xsp?id=WDU19970280152 (accessed on 28 October 2019).

20. Piccinni P, Cruz DN, Gramaticopolo S, et al. Prospective multicenter study on epidemiology of acute kidney injury in the ICU: a critical care nephrology Italian collaborative effort (NEFROINT). Minerva Anestesiol. 2011; 77(11): 1072-83.

21. Lai TS, Shiao CC, Wang JJ, et al. Earlier versus later initiation of renal replacement therapy among critically ill patients with acute kidney injury: a systematic review and meta-analysis of randomized controlled trials. Ann Intensive Care 2017; 7(1): 38. DOI: 10.1186/s13613-0170265-6.
22. Yang XM, Tu GW, Zheng JL, et al. A comparison of early versus late initiation of renal replacement therapy for acute kidney injury in critically ill patients: an updated systematic review and meta-analysis of randomized controlled trials. BMC Nephrol. 2017; 18(1): 264. D0l: 10.1186/s12882-017-0667-6.

23. Besen BAMP, Romano TG, Mendes PV, et al. Early Versus Late Initiation of Renal Replacement Therapy in Critically III Patients: Systematic Review and Meta-Analysis. J. Intensive Care Med. 2017; 1:885066617710914. DOl: 10.1177/0885066617710914.

24. Feng YM, Yang Y, Han XL, Zhang F, Wan D, Guo R. The effect of early versus late initiation of renal replacement therapy in patients with acute kidney injury: A meta-analysis with trial sequential analysis of randomized controlled trials. PLoS One 2017; 12:e0174158. Dol: 10.1371/journal. pone. 0174158 .

\section{ORCID and contributionship}

Agnieszka Wiórek - 0000-0002-8264-404X ${ }^{A, B, C, D, E, F}$

Milena Horodecka - $B, C, D, E, F$

Łukasz Krzych - 0000-0002-5252-8398 A,B,C,D,E,F

\section{Conflicts of interest:}

Authors declare no conflicts of interest.

\section{CORRESPONDING AUTHOR Łukasz J. Krzych}

Department of Anaesthesiology and Intensive Care

School of Medicine in Katowice

Medical University of Silesia, Katowice

14 Medykow Street, 40-752 Katowice, Poland

tel/fax +48327894201

e-mail: Ikrzych@sum.edu.pl

Received: 11.02 .2020

Accepted: 21.05 .2020

A - Work concept and design, B - Data collection and analysis, C - Responsibility for statistical analysis, D-Writing the article, $\mathbf{E}-$ Critical review, $\mathbf{F}-$ Final approval of the article 